\title{
Experimental investigation of interactions between the perennial red alga Gelidium pusillum and barnacles on a New South Wales rocky shore
}

\author{
Peter Jernakoff* \\ Department of Zoology, AO8, University of Sydney, 2006 New South Wales, Australia
}

\begin{abstract}
On rocky shores in New South Wales, the perennial red alga Gelidium pusillum (Stackhouse) Le Jolis occurs only within a midshore barnacle zone. This alga was rarely found to recruit from propagules but instead persisted as patches within the zone. Although barnacles did not influence the growth rate of $G$. pusillum they were crucial to the survival of the patches. $G$. pusillum that had overgrown the barnacle Tesseropora rosea Krauss stabilized the dead tests, thus postponing the reallocation of bare space on the shore otherwise available for settlement by other organisms. Survival of juvenile herbivorous molluscs sheltering in tests was also affected by the abundance of an algal covering over the barnacle shells. Results suggest that many interactions are taking place and that some of these can have opposite effects depending upon the abundance of component species.
\end{abstract}

\section{INTRODUCTION}

Despite numerous studies of the ecology of intertidal perennial algae elsewhere in the world (e.g. Dayton 1973, Lubchenco 1978, 1983, Schonbeck \& Norton 1978, 1979, 1980, Gunnill 1980, Oliger \& Santelices 1981, Santelices et al. 1981, and many others) few investigations of these types of algae have been reported for rocky shores of southeastern Australia. Perennial algae occurring along this coast have, however, been mentioned in descriptive studies of zonation patterns of intertidal organisms (Dakin et al. 1948, Dakin 1969), as well as in a detailed quantitative survey of patterns of vertical zonation of plants and animals along a rock platform in eastern Australia (Underwood 1981).

The perennial red alga Gelidium pusillum (Stackhouse) Le Jolis is found on New South Wales rocky coasts only in a midshore region dominated by barnacles (Underwood 1981). This barnacle zone lies between 0.4 and $1.6 \mathrm{~m}$ above Indian Low Water Spring Tide level (datum) for Sydney and is exposed to moderate wave action. The exposed nature of the zone is

\footnotetext{
- Present address: CSIRO Marine Research Laboratories, P.O.
} Box 20, North Beach, 6020 Western Australia generally typical of the habitat where $G$. pusillum has been reported to occur (e.g. Africa: Lawson 1966, Trinidad: Richardson 1969, Hawaii: Santelices 1977) although the alga was found on muddy substrata in places with slight water movement in southern Australia (Womersley \& Edmonds 1958).

The alga grows to a height of $2.5 \mathrm{~cm}$ and is composed of dense short tufts of erect fronds rising from cylindrical creeping axes (150 $\mu \mathrm{m}$ diameter) while erect axes are compressed and flat $(0.5 \mathrm{~mm}$ wide). Although Gelidium pusillum forms conspicuous patches growing on and amongst barnacles it is rarely observed to recruit from colonizing propagules. The lack of successful recruitment is not due to the grazing activities of herbivores (Jernakoff 1985) but perhaps to a harsh physical environment, to infertility, and/or to lack of spores (Santelices 1974). G. pusillum is also the only perennial macroalga that appears to maintain stable, moderately-sized, randomly distributed patches at mid-shore levels. One of the most striking features of the alga is its close association with a coronuloid barnacle, Tesseropora rosea Krauss. This type of association has not been reported for $G$. pusillum elsewhere in the world. In some areas, large numbers of dead barnacles are found covered by the alga (Jernakoff \& Fairweather 1985). Carnivorous whelks rather than $G$. 
pusillum are responsible for mortality of barnacles (Jernakoff \& Fairweather 1985) although some areas where whelks have not been seen for at least 1 yr still have a large proportion of dead barnacle tests that are either fused together or covered by algae. Small molluscs are sometimes found within tests, perhaps finding there a refuge from wave-action (Creese 1982, Underwood et al. 1983).

The aims of the present study were to determine: (i) the extent of stability of the algal patches and also of barnacle tests which may occupy space otherwise available for settlement of larvae and algal propagules of several species; (ii) the spatial pattern of algal patches and seasonal appearance of spores necessary for colonization; (iii) the influence of the algal-barnacle association on small molluscs sheltering within the tests.

\section{MATERIALS AND METHODS}

Experiments were done on sandstone platforms of the Cape Banks Scientific Marine Research Area, Botany Bay, New South Wales, Australia. Detailed descriptions of the areas can be found in Underwood (1981) and Jernakoff (1983).

Patches of Gelidium pusillum occurred in the lower two-thirds of the barnacle zone $(0.4$ to $1.2 \mathrm{~m}$ above Indian Low Water Spring Tide Level, datum for Sydney) and appeared from casual observation to be randomly distributed. Because algal clumps varied in size and shape, the spatial pattern of the patches was examined by Pielou's (1964) sampling method. There may be spaces within the patches as well as gaps between them. Thus, before sampling, the investigator must decide how big a space is for it to be regarded as a true gap. If the minimum size of a gap is ' $r$ ', any vegetation lying within a circular quadrat of radius ' $r$ ' is taken as part of a patch. This is scored as a 'hit' If there is no vegetation in the quadrat, the area is taken to be a 'gap' (i.e. between patches) and is scored as a 'miss'. If the population is sampled by quadrat-pairs and the distance between the quadrats (centre to centre) is ' $d$ ' $\geq 2 r$ then one of 3 events must occur: both quadrats score hits, both score misses or one scores a hit and the other scores a miss. If, relative to the sizes of patches and gaps, ' $d$ ' is very large then the 2 quadrats are virtually independent of each other and the frequency of these events will be binomially distributed. For small values of ' $d$ ', independence will not be obtained; if one quadrat scores a hit, the other is likely to do so as well. By sampling the population several times using paired quadrats of different distances apart, the results will consist of several different observed distributions of the 3 possible events. Conclusions about the dispersion and mean size of patch and gap can then be obtained by the methods described by Pielou (1964).

The spatial pattern of patches of Gelidium pusillum was sampled during winter at 2 sites at Cape Banks (Site 1 and Site 2) and also on another rock platform at Green Point (30 km north of Cape Banks). In addition, the reproductive condition of the alga was monitored at Cape Banks for 33 mo (March 1980 to November 1982).

The influence of barnacles on Gelidium pusillum was investigated at Site 2 at Cape Banks by monitoring the survival and growth of 10 algal patches where barnacles ( $2 \mathrm{~cm}$ basal diameter, $1.5 \mathrm{~cm}$ high) were present, and 10 where barnacles were experimentally removed. The sizes of patches were calculated from tracings on acetate sheets every month (December 1980 to June 1982) and converted to proportion of original patch-size. Any patch that had shrunk in size to less than $4 \mathrm{~mm}$ (diameter) could not be accurately recorded and was scored as zero cover.

Stability of barnacle tests that were fused together and/or covered by algae was examined by monitoring the rate of loss of either fused or isolated tests covered by or bare of Gelidium pusillum. At each of another 5 sites at Cape Banks, 10 isolated barnacles and 10 barnacles whose tests were fused together and covered by $G$. pusillum were killed by forcing a probe through the opercular plates. The number of tests remaining within the 5 study sites was recorded every 2 wk and compared with the same number of dead control tests (bare of algae).

Barnacles are known to act as shelter for molluscs from the effects of wave action and desiccation (Burrows \& Lodge 1950, Lewis \& Bowman 1975, Choat 1977. Creese 1982). The role of shelter was examined by counting the numbers of the 2 most numerous molluscs in the zone, Littorina unifasciata Grey and Patelloida latistrigata Angas, sheltering inside tests $(n=$ 20) either bare of algae, partially covered, or completely covered by Gelidium pusillum.

\section{RESULTS}

\section{Reproductive state}

Thalli of plants always contained tetraspores. The spores were most developed at the beginning of spring (September), after which scars could be seen in the thalli following spore-release. Attempts to culture propagules of Gelidium pusillum in the laboratory were never successful and there were only 5 occasions in 33 mo when adult plants were seen to recruit successfully from either spores or very small vegetative fragments (Mairh \& Rao 1978). 
Table 1. Gelidium pusillum. Analysis of the spatial pattern of clumps (see Pielou 1964). Size of each area sampled $=8 \mathrm{~m}^{2}$. Minimum size of gap $=2 \mathrm{~cm}$ radius. Length of quadrat pairs $=4,8,16,20$ and $24 \mathrm{~cm}$. Number of replicates for each independent quadrat pair $=100$

\begin{tabular}{|c|c|c|c|}
\hline & Site 1 & Site 2 & Green Point \\
\hline$\chi^{2}(10 \mathrm{df})$ & $24.1 P<0.05$ & $14.8 P>0.05$ & $10.23 P>0.05$ \\
\hline Pattern & Clumped & Random & Random \\
\hline Patch-size $(\mathrm{cm})$ & 19.1 & 7.1 & 6.9 \\
\hline Gap-size $(\mathrm{cm})$ & 53.6 & 14.2 & 33.9 \\
\hline Proportion of total area & 0.2 & 0.3 & 0.2 \\
\hline
\end{tabular}

\section{Patch-size and dispersion}

The distribution of patches at one site at Cape Banks (Site 1) and also at Green Point was random. While the patch-size was similar at the 2 sites, the average distance between the patches varied as did the proportion of total area of the substratum that the patches occupied (Table 1). At the other site at Cape Banks (Site 2), the patches of Gelidium pusillum were much larger and were clumped. Coverage by the alga was no greater than $30 \%$ at any site.

\section{Growth rate and survival of algal patches}

Patches of Gelidium pusillum underwent a reduction in size during the beginning of 1981 (summer) followed by an increase to more than their original size
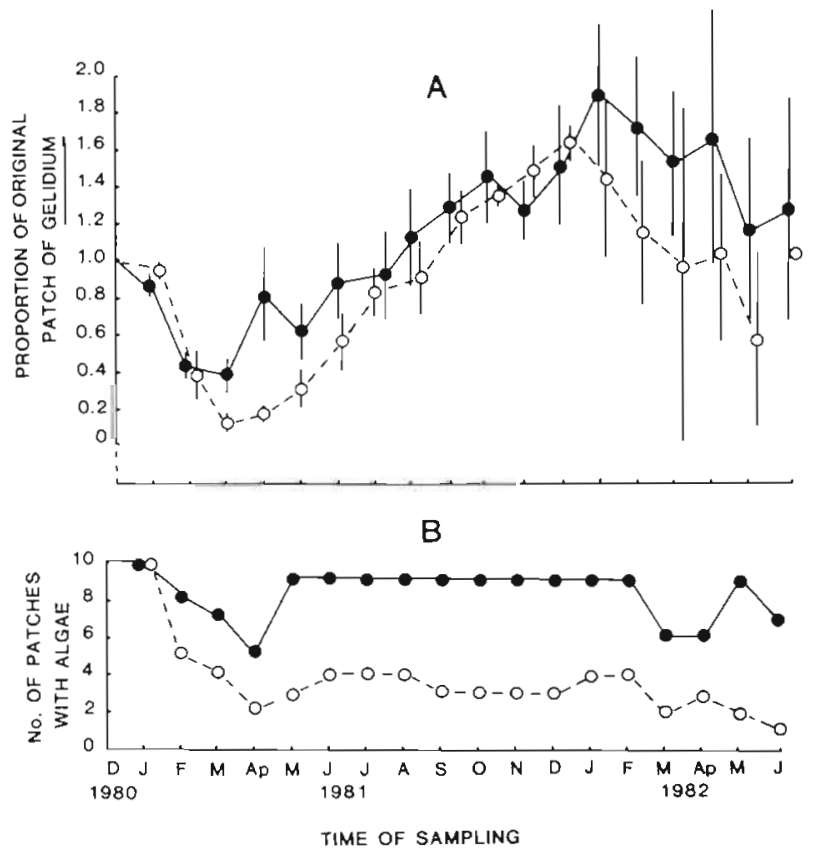

Fig. 1. Gelidium pusillum. Survivorship and change in patchsizes at Cape Banks, Site 2. (A) Proportion of original patchsize (mean $\pm S E$ for surviving patches). (B) Number of patches where algae were present. Means for $(\bullet) 10$ patches with barnacles, and (o) 10 patches without barnacles towards the end of 1981 (spring). The size of surviving patches was more variable during 1982 (Fig. 1A). There was no consistent difference in rate of growth, nor decline in size, of patches growing on barnacles compared with control areas. Significantly more patches, however, survived where barnacles were present (Fishers exact test $P=0.05$; Fig. 1B). Increase in the number of patches with algae (Fig. 1B) were due to patches that had declined to less than $4 \mathrm{~mm}$ (recorded as dead) growing again.

\section{Rate of loss of empty barnacles}

The opercula of dead barnacles were rapidly overgrown by Gelidium pusillum. The alga stabilized the tests, holding them onto the substratum. Some tests were no longer attached to the rock surface and were held in place only by the alga. The loss of tests without algae was far greater than of tests covered by $G$. pusillum (Fig. 2).

Barnacle tests not covered by algae that were fused in clumps with their neighbours remained on the shore for a much longer period of time than isolated individuals. The latter declined by $50 \%$ during the first $2 \mathrm{wk}$. After 10 mo there were still one-third of the fused bare tests left, compared with no single tests (Fig. 2).

No animals were found in tests completely overgrown by Gelidium pusillum; these tests contained a fine sediment and anoxic sludge. There were some juvenile gastropods present in partially overgrown shells. The greatest density of animals was found in tests completely bare of G. pusillum (Table 2).

\section{DISCUSSION}

Gelidium pusillum maintained its coverage on the shore by vegetative growth of long-lived algal clumps rather than by numerous recruiting propagules. In other parts of the world, perennial algae have been observed to recover by vegetative growth from disturbances that denude substrata (e.g. Sousa 1980). In 


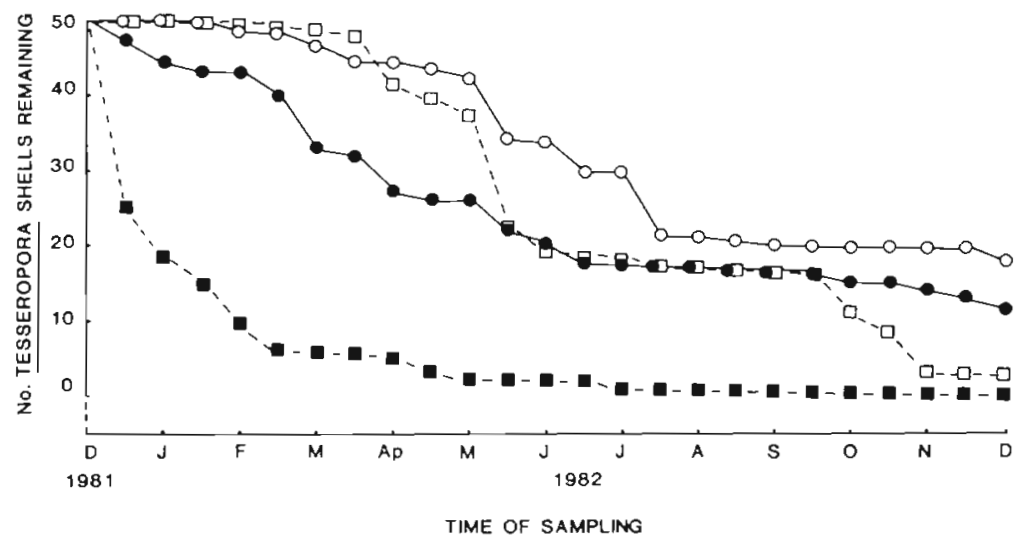

Fig. 2. Tesseropora rosea. Number of tests on the shore. ( $\bullet$ Individual barnacles covered by algae $(0)$ barnacles covered by algae and with tests fused together; (n) individual bare barnacles; ( $\square$ ) bare barnacles with tests fused together

Table 2. Mean number ( $\pm \mathrm{SE} ; n=20$ barnacles) of grazers found in barnacle tests

\begin{tabular}{lcc|}
\hline & Patelloida latistrigata & Littorina unifasciata \\
\hline No G. pusillum & $1.29 \pm(0.98)$ & $3.10 \pm(0.58)$ \\
Partial G. pusillum & $0.10 \pm(0.07)$ & $0.55 \pm(0.21)$ \\
Complete cover of G. pusillum & 0 & 0 \\
\hline
\end{tabular}

Sousa's study, however, plants could colonize from propagules but the germilings were usually outcompeted by ephemeral algae. The reason G. pusillum rarely recruited from propagules is unknown. The presence of tetrasporangial thalli, lack of seasonal periodicity, and poor ability to colonize areas (even in the absence of grazers; Jemakoff 1985) was consistent over the 33 mo of the study. The poor ability of Gelidium spp. to colonize areas was also found by Montalva \& Santelices (1981). These workers found that even 3 yr after clearing, $G$. filicinum Bory and G. lingulatum (C. Agardh) J. Agardh had not recovered half of the space they originally occupied. The lack of successfully recruiting propagules of G. pusillum may be due to infertility of propagules. This has been reported for other gelidioid algae (Santelices 1974).

Although the growth of Gelidium pusillum was the same regardless of the presence of barnacles, significantly more patches of algae survived where the growth was on live barnacles. This increased survival may have been due to increased moisture trapped by the alga around barnacles, thus reducing desiccation. Alternatively, the surface texture of barnacles may have provided a better site for attachment than bare rock, or perhaps survival was higher because barnacles broke up the water flow compared to areas of bare rock (some subtidal gelidioid algae are influenced by water-flow; Santelices 1978).

It is not clear whether the physical structure of barnacles, or the presence of live barnacles, was necessary for the survival of the patches of algae. Other experiments using fibreglass replicas of barnacle tests were unsuccessful because of Gelidium pusillum's slow rate of colonization (Jernakoff unpubl.). Indirect evidence suggests that the physical structure of the barnacle test is important. Algae growing over experimentally killed barnacles survived for up to 10 mo until the tests and algae were washed away by waves.

The increased stability of tests when fused to neighbours or covered by alga delayed the opening up of bare space that would otherwise be available for settling organisms. Overgrowth of sessile organisms resulting in the barnacles' death and detachment is a known method of creating space (e.g. Dayton 1973). In the present study, however, loss of barnacles led to reduced survival of Gelidium pusillum.

The interaction between Gelidium pusillum, Tesseropora rosea tests, and juvenile grazers (Littorina unifasciata and Patelloida latistrigata) that sheltered in dead tests varied depending upon the amount of algal overgrowth. Although more juvenile grazers sheltered in tests free of algae, these tests were not necessarily the best places in which to shelter. Bare tests were quickly washed away by the waves that also wash away unprotected juvenile grazers (Creese 1982 Underwood et al. 1983). On the other hand, any organism sheltering in the most stable (completely covered) tests would be smothered by sediment. Hence, the quality of shelter (in terms of stability and sediment burial) was a function of algal cover. Underwood et al. (1983) also found that other interactions among barnacles, algae, and grazers varied depending upon the relative abundance of the organisms. For example, the successful recruitment of barnacles could be influenced by the densities of the herbivorous limpet $\mathrm{Cel}$ lana tramoserica Sowerby. 
In conclusion, the present study reveals that a multitude of interactions are taking place between animals and Gelidium pusillum. Some of these interactions can be subtle while others are dramatic, but most have been demonstrated to be important in shaping the structure of this community.

Acknowledgements. This research was funded by a University of Sydney Research Grant and forms part of my Ph. D. dissertation. The help of my supervisor A. J. Underwood, and his comments on this paper, as well as those of an anonymous referee, are gratefully acknowledged.

\section{LITERATURE CITED}

Burrows, E. M., Lodge, S. M. (1950). A note on the interrelationships of Patella, Balanus and Fucus on a semi-exposed coast. Rep. mar. biol. Stn Port Erin 62: 30-34

Choat, J. H. (1977). The influence of sessile organisms on the population biology of three species of acmaeid limpets. J. exp. mar. Biol. Ecol. 26: 1-26

Creese, R. G. (1982). The distribution and abundance of the limpet Patelloida latistrigata, and its interaction with barnacles. Oecologia (Berl.) 52: 85-96

Dakin, W. J. (1969). Australian seashores (rev. ed.). Angus \& Robertson, Sydney

Dakin, W. J., Bennett, I., Pope, E. (1948). A study of certain aspects of the ecology of the intertidal zone of the New South Wales coast. Aust. J. Sci. Res. Ser. B. 1: 176-230

Dayton, P. K. (1973). Dispersion, dispersal, and persistence of the annual intertidal alga, Postelsia palmaeformis Ruprecht. Ecology 54: 433-438

Gunnill, F. C. (1980). Recruitment and standing stocks in populations of one green algae and five brown algae in the intertidal zone near La Jolla, California during 1973-1977. Mar. Ecol. Prog. Ser. 3: 231-244

Jernakoff, P. (1983). Factors affecting the recruitment of algae in a midshore region dominated by barnacles. J. exp. mar. Biol. Ecol. 66: 17-31

Jernakoff, P. (1985). An experimental evaluation of the influence of barnacles, crevices and seasonal patterns of grazing on algal diversity and cover in an intertidal barnacles zone. J. exp. mar. Biol. Ecol. 88: 287-302

Jernakoff, P., Fairweather, P. G. (1985). An experimental analysis of interactions among several intertidal organisms. J. exp. mar. Biol. Ecol. 94: in press

Lawson, G. W. (1966). The littoral ecology of West Africa. Oceanogr. mar. Biol. A. Rev, 4: 405-488

Lewis, J. R., Bowman, R. S. (1975). Local habitat-induced variations in the population dynamics of Patella vulgata L. J. exp. mar. Biol. Ecol. 17: 165-203
Lubchenco, J. (1978). Plant species diversity in a marine intertidal community: importance of herbivore food preference and algal competitive abilities. Am. Nat. 112: 23-39

Lubchenco, J. (1983). Littorina and Fucus: Effects of herbivores, substratum heterogeneity, and plant escapes during succession. Ecology 64: 1116-1123

Mairh, O. P., Rao, P. S. (1978). Culture studies on Gelidium pusillum (Stackh.) Le Jolis. Botanica mar. 21: 169-174

Montalva, S., Santelices, B. (1981). Interspecific interference among species of Gelidium from central Chile. J. exp. mar. Biol. Ecol. 53: 77-88

Oliger, P., Santelices, B. (1981). Physiological ecology studies on Chilean algae. J. exp. mar. Biol. Ecol. 53: 65-75

Pielou, E. C. (1964). The spatial pattern of two-phase patchworks of vegetation. Biometrics 20: 156-167

Richardson, W. D. (1969). Some observations on the ecology of Trinidad marine algae. Proc. Int. Seaweed Symp. 6: $357-363$

Santelices, B. (1974). Gelidioid algae: A brief resume of the pertinent literature. Tech. Rep. 1. Univ. of Hawaii

Santelices, B. (1977). A taxonomic review of Hawaiian Gelidiales (Rhodophyta). Pacif. Sci. 31: 61-84

Santelices, B. (1978). Multiple interaction of factors in the distribution of some Hawaiian Gelidiales (Rhodophyta). Pacif. Sci. 32: 119-147

Santelices, B., Montalva, S., Oliger, P. (1981). Competitive algal community organization in exposed intertidal habitats from central Chile. Mar. Ecol. Prog. Ser. 6: 267-276

Schonbeck, M. W., Norton, T. A. (1978). Factors controlling the upper limits of fucoid algae on the shore. J. exp. mar. Biol. Ecol. 20: 79-89

Schonbeck, M. W., Norton, T. A. (1979). Drought hardening in the upper-shore seaweeds Fucus spiralis and Pelvetia canaliculata. J. Ecol. 67: 687-696

Schonbeck, M. W., Norton, T. A. (1980). The effects on intertidal fucoid algae of exposure to air under various conditions. Botanica mar. 23: 141-148

Sousa, W. P. (1980). The responses of a community to disturbance: The importance of successional age and species' life histories. Oecologia (Berl.) 45: 72-81

Underwood, A. J. (1981). Structure of a rocky intertidal community in New South Wales: Patterns of vertical distribution and seasonal changes. J. exp. mar. Biol. Ecol. 51: $57-85$

Underwood, A. J., Denley, E. J., Moran, M. J. (1983). Experimental analysis of the structure and dynamics of midshore rocky intertidal communities in New South Wales. Oecologica (Berl.) 56: 202-219

Womersley, H. B., Edmonds, S. J. E. (1958).General account of the intertidal ecology of South Australian coasts. Aust. J. mar. Freshwat. Res. 9: 217-260 